Under the FIDIC model, the employer is either the public sector or a private entity, whereas in PFI projects in the UK only the public sector is using this route to build/finance infrastructure projects. The crucial factor, however, is that UK PFl deals are dependent on private funding; this means that the public sector's bargaining hand is weakened since private sector financiers will invariably want maximum protection for their investments. The structure of the deals is also very different since most PFI contracts are service-orientated. This means that the construction part of the agreement is not the most important feature of the contract and therefore the negotiating position of the parties differs accordingly. (c)

\title{
The selection of arbitrators: another view
}

\author{
by K V S K Nathan
}

\begin{abstract}
In the January 1999 issue of Amicus Curiae, David Winter OBE of Baker \& McKenzie in his article 'The selection of arbitrators' set out the process of choosing an arbitrator, which he divided into 12 points in his summary. Here, Dr K V S K Nathan responds to Mr Winter's article and expresses his own views on the topic.
\end{abstract}

$\mathrm{I}$ read with interest the paper by David Winter OBE on 'The selection of arbitrators' in Issue 13 of Amicus Curiae (January 1999). I agree entirely with the author except for the fact that, under the conditions that exist in the real world, the selection of arbitrators is made by people with an imperfect knowledge of the individual arbitrators and the nature of the dispute. In my opinion, the focus should be on the process of selection rather than on the individual arbitrator. The selection process should be seen as fair and neutral and respect the autonomy of the parties in dispute. The product of this process would lead to an ideal arbitration, if not the ideal arbitrator.

By themselves, considerations of psychology of the individual arbitrator, bias and independence, leadership qualities and acceptability to all partics can mean different things to different people, or indeed mean little in a world of intrigue and interest groups and divisive politics. Appearances can be very deceptive. In the terms expressed in the article, the ideal arbitrator, or for that matter the ideal judge in a court of law, is an elusive creature of our imagination.

\section{PARTY EXPECTATIONS}

Since arbitration is the creation of the parties in dispute, one should look at the expectations of the parties themselves in the selection of an arbitrator or arbitrators. Obviously the ideal arbitrator would be one who would faithfully follow the wishes of the parties in regard to the expeditious conduct of the arbitration and making of the award This would be consistent with the goal of arbitration, namely a binding award in dispute. However, there will be questions of fact as well as of law to be determined in an arbitration and, therefore, one has to accept that individual arbitrators, like individual judges in a court of law, can come quite honestly to different conclusions. There can be a whole range of valuc judgments to be made and arbitrators, like their counterparts in the courts of law, can vary widely in their perceptions of matters before them and of the credibility of witnesses, but that does not signify bias one way or another or disqualify them from being arbitrators and judges. I do not think that we want arbitrators to be clones of one another.

From the perspective of a party in dispute, the ideal arbitrator would be someone who would hopefully support the party's case in the matter in dispute. Where the party has the right to nominate an arbitrator, it is bound to look for someone who will perceive and interpret the facts and law of the case in a manner favourable to the party concerned. The party would be interested not only in the arbitrator's background qualifications and experience but also his or her views as expressed in a variety of contexts, such as public statements, law journals, previous awards and so on. There is nothing wrong in a party selecting as arbitrator someone whom he or she thinks would be sympathetic to his or her case. That the arbitrator thinks one way or another is not always an indication of bias but rather an illustration of his or her powers of reasoning and intellect. Reading the criteria listed in the article, one might be tempted to think that it may be prudent for arbitrators to keep their views on issues of the day to themselves, because the devil one does not know would seem to be better that the devil one knows. That would be harmful to the whole adjudicatory process, where onc is searching for the truth. Truth is most likely to be discovered 
by exposure to the scrutiny of those with varying views and standpoints and their interaction in a rational manner.

Unfortunately, arbitral proceedings conducted by single arbitrators may not provicle the opportunity for this interaction, and the appointment can occasionally be a gamble in that the person chosen may prove not to have an open mind in regard to the matter before them. In the courts system the appellate process will provide the desirable scrutiny to correct any miscarriage of justice, albeit at different levels of the judicial process. There is some validity in the current thinking among arbitration circles that an appellate facility should be available in arbitrations, but that would increase arbitration costs which are already high. Under some national arbitration laws, the local courts exercise a degree of control over the conduct of domestic arbitrations and therefore, single arbitrators may be justified, at least in cases involving small sums of money. In international arbitrations, on the other hand, in the absence generally of an appellate facility, a multi-member tribunal should normally be preferred to a single arbitrator, as it reduces the chances of a binding rogue award.

Independence means only one thing: namely, that the arbitrator is a person capable of exercising his dutics independently of any fallout from past or present relationships personal, professional or public - with the parties involved in the dispute and, in a multi-member tribunal, the arbitrators themselves should be capable of independent thinking and analysis without regard to past or present relationships inter se.

Closeness of relationship, such as being the spouse, parent or child of a party or his chief counsel, is clearly a factor to be considered and is a matter that can easily be verified without resorting to any subjective evaluation. They are obvious grounds for disqualifying a nominee as arbitrator, but in some cultures where family, name, traditions and ties play an important role in public and private life, even remoter relationships may have to be tested. The evaluation of private professional relationships (because of the fact that arbitrators can, for example, also be successful lawyers or engineers or quantity surveyors in private practice) can be a thorny problem in an increasingly interactive world. In so far as international arbitrations are concerned, I would exclude consideration of professional relationships, except where the relationship is one of professional and client or employer and cmployee, or has been so in the recent past, and the conflict of interests is plain for the world to sec.

To a lesser extent, the nature of relationships in a public capacity can also be reasonably verified, although such relationships may be advantageous to a nominee as arbitrator because of his or her awareness of the rules of fairness and due process in the exercise of his or her duties as a public servant. This accounts for a general acceptance that a government engineer in a department involved in a project, or a government lawyer, is qualified to be an arbitrator in a dispute arising out of - a contract where the government is a party. Unfortunately, even in the advanced democratic societies, burcaucrats and their political masters cannot always be trusted to act in an unbiased and impartial manner because often there is so much at stake for them personally in terms of power and money.

Institutional arbitral rules, such as those of the International Chamber of Commerce (ICC) and the London Court of International Arbitration (LCIA), usually provide for final approval of the party nominees by the institutions themselves, but this power, in the interests of respect for party autonomy, should be exercised in a responsible manner and very sparingly.

\section{Psychological attributes}

I would question the emphasis given to some of the so-called psychological attributes of the arbitrator. I do not believe that a person who puts himself forward as an international arbitrator would not like to travel abroad. In any case, the arbitrator before accepting a nomination, would have weighed several considerations, including questions of travel abroad and visiting sites under difficult conditions and with few facilities. The person who is responsible for selection of an arbitrator should not substitute his own judgment in regard to this, because he may lose the services of an otherwise excellent arbitrator on grounds that can be mere conjecture.

Frequent travel and residence abroad is not proof that a person is comfortable with people from other countries and cultures and I do not sec a connection between being socially comfortable with other peoples and being impartial and fair. Besides residence abroad can be used for and against a candidate for selection as arbitrator if, for instance, the dispute arises from a transaction in a country where the candidate has resided. Most Europeans when they live abroad tend to live in their own enclaves, socialise among themselves in their own clubs and interface with the locals (they used to call them natives), only infrequently at formal occasions if at all. One may be forgiven for thinking that a European who has not been abroad may be more open and impartial than someone who has travelled and lived in a developing country. Those who have lived abroad can develop a strong bias against the indigenous people. Generally they do not trust them, as is reflected in the higher standard of proof often demanded by international arbitrators from a party and witnesses from a developing country.

\section{ACCEPTABILITY}

Acceptability to all parties would necessarily apply to arbitrations conducted by single arbitrators but where a tribunal of more than one member is involved in the proceedings acceptability should not be a requirement unless the arbitration agreement or rules specifically provide for this. The practice in English domestic construction arbitrations for the parties to come up with a list of arbitrators rather than simply name their nominees is an attempt to weaken the autonomy of the parties. It should have no place in international arbitrations because it enables the stronger party in terms of power and influcnce to prevail in the selection of arbitrators. It inevitably results in arbitrations being conducted by a narrow circle of arbitrators or could make the appointment of an arbitral tribunal a tortuous protracted process

Provisions are made in all arbitration rules for the intervention of an appointing authority in the selection of arbitrators under certain circumstances. However, any invasion of a party's autonomy in the selection of arbitrators should be resisted, for the reason that a party and its counsel nominating an arbitrator would be doing so with a heavy heart and an acute awareness of the responsibility a nominee has to bear in the arbitration, the outcome of which will affect that party so intimately. Under modern arbitration rules, the party nominating should know that it would be an act of futility, if not 
folly, to nominate a person who is likely to be prejudiced and unreasonable, The arbitral rules will ensure that even under the worst choice of arbitrators, the arbitral process can be led to a successful conclusion.

One may be inclined to suggest, therefore, that special criteria should be applied to the selection of a chairman of a tribunal and that the co-arbitrators may be lesser creatures. I do not think that one can realistically search the four corners of the world to locate a paragon of virtue nor that character committees of professional bodies are the answer. The co-arbitrators should be encouraged to select their own chairman; they are going to work with him or her for a length of time and interact at a personal level at the hearings and afterwards. The risk that the chairman will be a person of bias, lack independence and favour one side of the other, is slight, where in the selection of the co-arbitrators the autonomy of the nominating parties in the dispute is respected. The co-arbitrators will then ensure that the chairman would be an independent and neutral person at worst but sufficiently strong-minded to have the courage to exercise the unique powers given to him or her by modern arbitral rules.

\section{LOGIC AND REASON}

That leads me to the most valuable feature of arbitrators. They should tenaciously follow logic and reason and have the judicial acumen to be able to recognise when one side or the other has a stronger position in regard to a matter of fact or law. In other words, arbitrators should be chosen primarily for their intellectual and analytical skills. It is often said that we need arbitrators who are practical people who can 'sniff and tell' the right decision, but anyone who has been involved in major international arbitrations knows how much a case can depend on the interpretation of an ambiguous word or phrase and a misplaced punctuation mark, and equally how much a case depends on the study and in-depth analysis of facts and law. Hundreds of documents and reams of transcripts of oral testimony are involved. You need arbitrators who can interact at that level of intellectual effort and who are willing to expend their energies to prove, sift, analyse and cut to the truth in the mire of claims and counterclaims and conflicting oral testimony and documentary evidence that usually confronts them.

It is nice to think of an arbitral tribunal as being a collegial team, but one cannot avoid the bickering that inevitably goes on among equals, even in the loftiest of judicial institutions, and the egos of arbitrators can be very strong indeed. Edward Lazarus, a former clerk of the US Supreme Court, in his book Closed Chambers, describes the court as:

'[a] body of nine independent opinionated judges whose views in hard cases often prove irreconcilable must above all preserve a decency of process. For the system to work, for Justices in disagreement to achieve an exchange of ideas, undertake a search for common ground, or even reach an agreement respectfully to disagree, there must be trust and belief in mutual good faith. There must be a sense that reasons matter more than specific outcomes.'

An arbitral tribunal is not a social club and members of the tribunal do not have to conform, but it is imperative that, in the end, they are driven not by their private prejudices but by the cold facts before them and the logical and reasonable outcome under the law. Even then they may not all agree on particular facts and the law as applied to those facts, but unanimity is not a requirement under almost all arbitral rules.
However, for the credibility of the arbitral process, it is vital that before moving to a decision the chairman ensures that opportunity is given for opposing views to be fully heard during deliberations of the tribunal. I would borrow again from Mr Lazarus, who pointed out that:

Justice Scalia, for example, has advanced the excellent idea that the Justices refrain from joining a draft majority opinion until the main dissent in that case has been circulated. Scalia's proposal, easily adopted, would have the salutary effect of promoting fuller consideration of opposing views.'

Arbitral tribunals may well profit from adopting a similar procedure, because the prior circulation of a dissenting minority opinion would have a sobering influence on the majority Fortunately, in practice, the arbitral process is rarely affected by the views of one or more arbitrators.

\section{CONCLUSION}

To put it in a nutshell, my finding is that the process of selection of arbitrators should be based on a healthy respect for he autonomy of the parties in dispute. Arbitration is a creation of the parties in dispute and they are the most concerned that the arbitral proceedings are conducted in an expeditious, fair and impartial manner. The fact that disruption of the process inevitably results in increased costs should encourage most parties, except perhaps those rare parties with an agenda other than the resolution of the dispute they are involved in, to nominate arbitrators with the integrity to respect the arbitral process. They are ideal arbitrators regardless of the fact that the nominating party may have appointed him or her for reasons of self-interest. A party-nominated arbitrator may appear to be a biased person to the other side, but could nevertheless be an ideal arbitrator from the point of view of conducting a successful arbitration.

I believe that the parties can be relied upon to nominate the ideal arbitrators. I would expect them to choose arbitrators who would:

- believe in the arbitral process as a cost-effective alternative to the ccurts system to ensure that the proceedings are conducted expeditiously;

- have high intellectual and analytical skills, be prepared to expend the time and energy to examine thoroughly the case before them and be driven exclusively by logic and reason; and

- have the capacity to interact with their fellow arbitrators and the chairman in a rational manner.

A large measure of agreement is usually possible between logical and reasonable people. It goes without saying that, left to the parties, they will choose persons who also have some knowledge and experience in the subject matter of the dispute or in whom they have great confidence. They would be ideal arbitrators from my point of view, not because they would be paragons of virtue, but because their product would be an ideal arbitration.

\section{Dr KVSK Nathan}

Barrister/arbitrator, Italy 